\title{
Income taxation and equity: new dominance criteria and an application to Romania*
}

\author{
P. Brunori ${ }^{\dagger}$ F. Palmisano ${ }^{\ddagger}$ V. Peragine ${ }^{\S}$
}

November 12, 2014

\begin{abstract}
This paper addresses the problem of the normative evaluation of income tax systems and income tax reforms. While most of the existing criteria, framed in the utilitarian tradition, are uniquely based on information about individual incomes, this paper, building upon the opportunity egalitarian theory, proposes new equity criteria which take into account also the socio-economic characteristics of individuals. Suitable dominance conditions that can be used to rank alternative tax systems are derived by means of an axiomatic approach. Moreover, the theoretical results are used to assess the redistributive effects of an hypothetical tax reform in Romania through a microsimulation analysis.
\end{abstract}

Keywords: income inequality; inequality of opportunity; tax reforms; microsimulation; progressivity; horizontal equity.

JEL Classification: D63, E24, O15, O40.

${ }^{*}$ The empirical section of this paper would not have been possible without the financial support of the the Inclusive Growth Research Infrastructure Diffusion project funded by the European Union's $7^{\text {th }}$ Framework Programme for Research. The use of EUROMOD on 2011 incomes was made possible thanks to the patient support of Holy Sutherland, Silvia Avram, Iva Tasseva. We are grateful to participants at the ISER Policy, Income and Welfare Research Group meeting, University of Essex and at the 2014 SIEP Conference, University of Pavia.

†Università di Bari. E-mail: paolo.brunori@uniba.it

$\ddagger$ University of Luxembourg. E-mail: flaviana.palmisano@uni.lu

$\S$ Università di Bari. E-mail: vitorocco.peragine@uniba.it 


\section{Introduction}

The normative assessment of income tax reforms most often consists of comparing the postreform distribution of individual welfare with the pre-reform distribution or possibly that obtained from another reform. This comparison is carried out either by using a specific, utilitarian, social welfare function, as it is the case in the optimal income tax literature (Mirlees 1971), or by using a family of social evaluation criteria, as in the social choice tradition, thereby obtaining only a partial ranking of tax reforms (see for instance Lambert, 2001). Both these approaches are generally framed in a rigorous welfarist conceptual framework: the individual position, either pre- and post- taxes, is evaluated only in terms of individual utility, which in turn is assumed to depend only on the individual income. Consistently, the equity criteria embedded into the social welfare functions, such as the horizontal and vertical equity principles, are expressed in terms of individual incomes and utilities.

On the other hand, a robust equity theory recently developed in the philosophical and economic literature has proposed opportunity, instead of income, as the proper space for equity judgments. This literature is based on the idea that a society can accept inequalities due to the individual responsibility while objecting to those due to exogenous circumstances. In fact, the ideal of equal opportunities is the product of two independent (and sometimes conflicting) principles: the principle of compensation, stating that differences in individual outcomes, unambiguously determined by differences in circumstances, are unfair and need to be compensated by the society; and the principle of reward, stating that differences in individual achievements unambiguously attributed to differences in effort are equitable. See Roemer (1998) and Fleurbaey (2008) for book-length discussions of the opportunity egalitarian theory and see Ferreira and Peragine (2014), Ramos and Van de gaer (2012) and Roemer and Trannoy (2013) for recent surveys of the literature.

The opportunity egalitarian theory may provide an alternative normative framework for the evaluation of tax reforms and tax systems. In particular, we believe that the opportunity perspective may help to lessen the ambiguity on the meaning of a 'just taxation' and may be more in tune with the popular preferences for redistribution in western liberal societies. In this paper we precisely address this issue, that is, the assessment of the impact of tax systems and tax reforms from the point of view of equality of opportunity.

Previous examples of applications of the Equality of opportunity (EOp) framework for the evaluation of different tax systems can be found in Roemer et al. (2003) and in Aaberge and Colombino (2012). Roemer et al. (2003) propose an optimal tax scheme model which is used as benchmark to evaluate which income-tax regime is able to equalize the opportunities in the income distribution within eleven European countries. Aaberge and Colombino (2012) propose a secondbest analysis and, by using a rich microsimulation model taylored on the Italian income tax, estimate the optimal taxation for both the utilitarian and the opportunity egalitarian criteria ${ }^{1}$. Although close in spirit to these papers, our work presents a distinctive feature: while their models are framed into the optimal income tax model $\grave{a}$ la Mirlees, we use a partial dominance approach, which is more in line with the social choice tradition and allows for a more robust ethical assessment. Hence we will be seeking for conditions of dominance of one income tax regime over another according to large families of opportunity egalitarian social evaluation functions.

To the best of our knowledge, our paper is the first attempt to address such issue.

The first step in our analysis consists in building a social welfare function expressing our ethical

\footnotetext{
${ }^{1}$ See also Jacquet and Van de gaer (2011) and Schokkaert et al. (2004) for an analytical discussion on the conflict between standard criteria in the optimal tax literature and the requirements of equality of opportunity.
} 
concerns. Now, the two basic principles of fairness in the theory of taxation are horizontal equity, prescribing the 'equal treatment of equals' (Musgrave 1959)2 and vertical equity, prescribing the 'differential treatment of unequals'. From the opportunity egalitarian viewpoint the variable in terms of which the individuals should be considered as equals, hence deserving equal treatment, or unequals, hence deserving some equalizing treatment, is their set of opportunities. Hence we need a tractable model of individual opportunities. To this end, following the EOp literature, we introduce a model in which the individual income is generated by a function that depends on two categories of factors: exogenous circumstances that lie outside the sphere of individual responsibility, assumed to be observable; and effort, which captures all the factors that are within the individual responsibility and is defined residually after the circumstances are accounted for. Once we have a multidimensional distribution of income and circumstances, we can partition the population into types, a type being a set of individuals characterized by the same circumstances. In the EOp literature the type specific income distribution, that is the income distribution conditional to circumstances, is interpreted as the opportunity set which is available ex ante to all individuals in that type. Accordingly, in the EOp framework the concept of horizontal equity can be formulated by looking at individuals sharing the same initial exogenous circumstances, that is belonging to the same type; while the vertical equity instead deals with individuals with different opportunities, i.e., belonging to different types. We will exploit this basic intuition in the paper and will translate it into formal axioms that will be imposed on the social evaluation functions.

Analytically, the evaluation of a tax system in our model will be based on two basic information at the individual level: (i) the set of characteristics outside the sphere of the individual responsibility, which determine the type of an individual, and (ii) the income change induced by the tax system. Hence we will characterize partial orderings defined over bi-dimensional distributions, where one distribution, the circumstances defining the type, is only ordinally measurable, while the second, the income change, is cardinally measurable and assumed to be continuous. These orderings will be coherent with social preferences endorsing the equality of opportunity principle.

The framework we propose can be used to complement the standard analysis of the redistributive effect of tax-benefit systems and may give interesting insights for the design of public policies. If two tax-benefit systems have, say, the same impact in terms of income inequality reduction, but in the first case all members of a given socio-economic groups who were the most disadvantaged before the tax reform are further impoverished by this reform, whereas in another case this impact is uncorrelated with differences in socio-economic characteristics, our current arsenal of measures fails to distinguish them. This kind of information can be extremely valuable for those policymakers involved in the implementation of mechanisms that target specif groups of the population.

Our contribution is analytically related to a recent paper by Bourguignon (2011), in which he proposes normative criteria to compare tax reforms that are sensitive to the status-quo of individuals in the pre-reform distribution. Our approach is similar to Bourguignon (2011), in that we both evaluate bidimensional distributions. However, Bourguignon (2011) adopts a standard utilitarian approach: in his model the identifying variable with respect to which the equity principles are formulated is the pre-reform individual income; while in our contribution the identifying variable is the type to which the individual belongs. Such difference clearly reflects the different underlying equity principles and leads to different welfare criteria.

In the paper we apply our theoretical framework to the evaluation of an hypothetical tax reform in Romania as compared to the tax regime in place. This country has been characterized by a peculiar tax history: the progressive system in place before 2005, based on a tax allowance and

\footnotetext{
${ }^{2}$ See, inter alia, Duclos and Lambert (2000), Jenkins and Lambert (1999) and Urban and Lambert (2008).
} 
five tax rates - ranging from $18 \%$ to $40 \%$ - was substituted by a $16 \%$ flat tax rate. This reform was motivated by the need to lessen tax evasion and avoidance and, indeed, this aim was successfully accomplished. By contrast, as it is not difficult to foresee, this tax change was proved to be quite regressive with the richest quantiles gaining disproportionally more than the poorest. In our analysis, we first evaluate the distributional impact of the actual system under the light of equality of opportunity, to understand whether this regime performs badly also when an opportunity egalitarian perspective is endorsed. We then compare this performance with that of an hypothetical reform, with same tax levy as the actual one, but based on four income brackets, with tax rates ranging from $15 \%$ to $30 \%$. In order to conduct this study we develop a microsimulation analysis using the Romanian Survey on Income and Living Conditions, Romanian implementation of the European Union Statistics on Income and Living Conditions (EU-SILC) collected in 2011. We find that the type of reform proposed in this paper could improve the distributional performance of the tax regime in place, not only when income inequality matters, but most importantly when opportunity represents the space of evaluation.

Hence, the contribution of this work is twofold. From a theoretical point of view, we propose a model for comparing different fiscal systems that is coherent with the norm of equality of opportunity. From an empirical point of view, we provide evidence for the need of a tax reform in Romania in order to improve its recent poor distributive performance.

The rest of the paper is organized as follows. Sections 2 contains the theoretical contribution of the paper: it (i) introduces the analytical framework and the standard utilitarian approach, then it (ii) introduces the EOp model and proposes families of opportunity egalitarian social evaluation functions, and finally it (iii) presents the theorems characterizing suitable dominance conditions. Section 3 presents the results of the empirical analysis. Section 4 concludes. The Appendix contains all the proofs.

\section{Tax systems comparisons}

In this section we first outline the set up and the standard utilitarian practice used to assess alternative tax systems and reforms, we then introduce our approach based on the opportunity perspective.

\subsection{The set up}

Let $F(y)$ be the initial cumulative distribution of income, with density $f(y)$, and consider a tax system $\tau$, where a tax system is nothing but a function $\tau: \mathbb{R}_{+} \rightarrow \mathbb{R}$ that associates a tax to a given level of income. We denote by $y_{\tau}$ the final level of income of an individual with initial income $y$ under tax $\tau$ and by $F\left(y_{\tau}\right)$ and $f\left(y_{\tau}\right)$ the relevant post tax cumulative and density distribution functions. Moreover, we denote by $\delta^{(\tau)}(y)$ the income change relative to income $y$ under tax $\tau$ and by $F\left(\delta^{(\tau)}(y)\right)$ the distribution of income changes. The income change can be interpreted either as absolute $\left(y_{\tau}-y\right)$ or relative $\left(\frac{y_{\tau}-y}{y}\right)$ income change.

Two interpretations are possible with our framework. In the first interpretation, the initial income $y$ is interpreted as pre-tax income and therefore $y_{\tau}$ is interpreted as post tax or net income under tax regime $\tau$. In this interpretation, the income change $\left|\delta^{(\tau)}(y)\right|$ corresponds to tax liability or average tax rates at income $y$, according to the absolute or relative interpretation, respectively. In the second interpretation, the initial distribution is interpreted as the status quo post-tax distri- 
bution, i.e., the distribution of net incomes obtained according to the existing tax system and $y_{\tau}$ denotes the level of income obtained by an individual with income $y$ under the alternative tax system $\tau$. Consequently, $\delta^{(\tau)}(y)$ denotes the income change at income $y$ when going from the existing tax system to the new tax system $\tau$. Hence, in the first interpretation the issue is that of evaluating and comparing tax systems; while in the second interpretation we are interested in evaluating and comparing tax reforms. Our results, as we will see, can be interpreted in both scenarios. In fact we will focus on the distribution of the income change $\delta^{(\tau)}(y)$. In our setting the income change $\delta^{(\tau)}(y)$ can take both positive and negative values: in the former interpretation that corresponds to allowing the possibility of a negative income tax, while in the latter interpretation it is normal that going from one tax system to another there are gainers and loosers.

The standard practice to evaluate the redistributive effect of a tax system (see Cowell 2000, Lambert 2001) consists in comparing the Lorenz curve associated to the pre-tax income distribution to the same curve associated to the post-tax distribution. In welfare terms, a dominance between the two curves, in fact, implies that the considered tax system is welfare-improving, for all utilitarian social welfare functions based on increasing and concave individual utility functions, with respect to an equal yield proportional tax. In the tax reforms interpretation, consider two alternative and equal yield tax reforms $\tau_{1}$ and $\tau_{2}$ : applying the standard approach, we can state that reform $\tau_{1}$ is preferred to reform $\tau_{2}$ according to all utilitarian criteria based on increasing and concave individual utility functions if and only if the Lorenz curve of the post-reform distribution under $\tau_{1}$ dominates the Lorenz curve of the post-reform distribution under $\tau_{2} 3^{3}$

\subsection{The EOp approach}

According to the EOp model (Roemer 1998, Fleurbaey 2008, Peragine 2004), the individual income $y$ is a function of two sets of characteristics: the circumstances, $\mathbf{c}$, belonging to a finite set $\Omega=\left\{\mathbf{c}_{1}, \ldots, \mathbf{c}_{n}\right\}$, and the level of effort, $e \in \Theta \subseteq \Re_{+}$. The individual cannot be held responsible for $\mathbf{c}$, which is fixed over time, but she is, instead, responsible for the effort $e$. Income is generated by a function $g: \Omega \times \Theta \rightarrow \mathbb{R}_{+}$, such that $y=g(c, e)$. This model excludes the existence of random components ${ }^{4}$ The function $g$ is assumed to be monotonic in circumstances and effort and it is the same for the whole population. Given an income distribution $F(y)$ and initial circumstances defined by $\Omega$, it is possible to partition this distribution into groups called 'types' and including all individuals sharing the same circumstances. For all $i=1, \ldots, n$, type $i$ is the set of individuals with circumstances $\mathbf{c}_{i}$; the income distribution of type $i$ is represented by $F_{i}(y)$, with population share $q_{i}$ and mean income $\mu_{i}(y)$.

We now introduce a tax $\tau$ : as before, we denote by $y_{\tau}$ the individual income after tax $\tau$ and by $F\left(y_{\tau}\right)$ the overall income distribution after tax. Hence we can write $F(y)=\sum_{i=1}^{n} q_{i} F_{i}(y)$ and $F\left(y_{\tau}\right)=\sum_{i=1}^{n} q_{i} F_{i}\left(y_{\tau}\right)$ for the initial and final distribution respectively. Given this analytical framework, the focus of the analysis is the income prospects of individuals of the same type, represented by the type-specific income distributions $F_{i}(y)$ and $F_{i}\left(y_{\tau}\right)$. These distributions are interpreted as the set of opportunities open to each individual in type $i$, respectively before and

\footnotetext{
${ }^{3}$ When evaluating a tax reform, these criteria assume that the ranking of individual incomes is the same before and after the reform, which happens very sporadically, instead. On the base of this observation, Bourguignon (2011) proposes an extension of this criteria in order to include status-quo concerns, where status quo is intended as the rank in the pre-reform distribution.

${ }^{4}$ See Van de Gaer (1993) and Lefranc et al. (2009) for an alternative approach which recognizes the role of luck, in addition to circumstances and effort, in determining the individual outcome.
} 
after $\operatorname{tax} \tau$. In other words, the observable actual incomes of all individuals in a given type is used to proxy the unobservable ex ante opportunities of all individuals in that type.

By a slight abuse of notation let us denote by $(F, \Omega)$ the resulting bivariate distribution and by $D$ the set of admissible distributions.

Let $F_{i}\left(\delta^{(\tau)}(y)\right)$ be the cumulative distribution function of the individual income change within type $i$ and let $\delta_{i}^{(\tau)}(p)$ be the income change generated by tax $\tau$ for an individual belonging to type $i$ and ranked $p$ in the distribution of income change specific to that type, $F_{i}\left(\delta^{(\tau)}(y)\right)$. That is, for each type $i, \delta_{i}^{(\tau)}(p)$ is the value of the left inverse cumulative distribution $F_{i}^{-1}\left(\delta^{(\tau)}(y)\right)$ at $p$, denoting the income change experience by the individual ranked $p$ in $F_{i}\left(\delta^{(\tau)}(y)\right)$. That is, $\delta_{i}^{(\tau)}(p):=\inf \left(\delta: F_{i}\left(\delta^{(\tau)}(y)\right) \geq p\right)$. Note that in this distribution individuals are sorted non decreasingly according to the level of their income change.

Within this framework, the social welfare evaluation associated to an income tax is assumed to be a function of the individual income changes and the individual original socio-economic conditions, as follows:

$$
W(F, \Omega, \tau)=\sum_{i=1}^{n} q_{i} \int_{0}^{1} v_{i}(p) \delta_{i}^{(\tau)}(p) d p
$$

Eq. (1) states that a social evaluation of a tax system is obtained as a weighted sum of income changes, where each income change is aggregated first within each type and than across types, where types are ordered according to their rank in the pre-tax distribution. Hence $\int_{0}^{1} v_{i}(p) \delta_{i}^{(\tau)}(p), \forall i=$ $1, \ldots n$ is the evaluation of the overall income change experienced in the type ranked $i$ in $F(y)$. The function $v_{i}(p):[0,1] \longrightarrow \Re_{+}$expresses the social weight attached to income change that takes place at $p$ in $F_{i}(\delta)$ (Yaari, 1988) ${ }^{5}$ That is, in order to evaluate a tax system, we aggregate the social welfare evaluation of the income change due to the tax experienced by each type, weighted by the relevant population share, using type-specific weighting functions. Different value judgments coherent with the EOp theory are expressed in this framework by imposing some properties on the 'social weight' functions, hence selecting different classes of weight profiles. These in turn define different classes of social evaluation functions (SEF).

We start by introducing a standard monotonicity assumption, implying that we prefer income increments to income reductions.

Property 0 (Monotonicity). $v_{i}(p) \geq 0$, for all $i=1, \ldots, n$ and for all $p \in[0,1]$.

According to Monotonicity, all else equal, a positive tax will not increase social welfare, whereas a negative tax will not decrease social welfare. The next property we consider is Within Type Neutrality.

Property 1 (Within Type Neutrality). For all $i=1, \ldots, n$ and $p \in[0,1], \exists \beta_{i} \in \Re_{+}$such that: $v_{i}(p)=\beta_{i}$.

This property, by making the weight only depending on the type, expresses the social irrelevance of possible differences in the impact of the tax among individuals in the same type. It is expression of the utilitarian reward principle (see Fleurbaey 2008). Given that we preserve anonymity within

\footnotetext{
${ }^{5}$ See Aaberge (2001) for a normative justification of the rank dependent approach in inequality analysis. See also Peragine (2002), Aaberge et al. (2011) and Palmisano (2011) for an application in the field of inequality of opportunity measurement and Andreoli et al. (2014) in the field of public policy evaluation.
} 
type, this amounts to say that any progressive or regressive transfer within the same type should not change the social evaluation.

The third property considered is the following.

Property 2 (Opportunity Vertical Equity). For all $p \in[0,1]$ and $i=1, \ldots, n-1: v_{i}(p) \geq v_{i+1}(p)$.

According to this property, an income reduction decreases more social welfare the more disadvantaged is the type where the reduction takes place. Symmetrically, an income increase brings more additional welfare the more disadvantaged is the type of the individual experiencing that increase. Thus, Property 2 reflects vertical equity with respect to individuals characterized by different starting socio-economic conditions. Technically the property says that the transfer of a small amount of income $\rho$, from a fraction $d p$ of the population at quantile $p$ of type $i$ distribution of income change due to tax to a fraction $d p$ of the population at the same quantile $p$ of type $j$ distribution of income change (with $p \in[0,1]$ and $j \leq i$ ), does not decrease social welfare, that is a transfer between individuals that have the same tax treatment within their respective type. Property 2 would prescribe the following changes: (i) augmenting the tax on a richer type in order to increase by the same amount the positive transfer to a poorer type; (ii) reducing the positive transfer of a richer type to increase by the same amount the positive transfer to a poor type; (ii) augmenting the tax on a richer type in order to reduce by the same amount the tax of a poorer type.

The last property we consider is:

Property 3 (Opportunity Horizontal Equity). For all $p \in[0,1]$ and $i=1, \ldots, n-1: v_{i}^{\prime}(p) \leq$ $v_{i+1}^{\prime}(p) \leq 0$

Property 3 introduces horizontal equity concerns, by prescribing that the lower is the level of inequality in the individual changes within a type, the higher is social welfare. A social evaluation function satisfying property 3 captures the inequality of the income changes, caused by the reform, conditionally on individuals' type. This property is introduced by Fleurbaey and Peragine (2013) and interpreted as a minimal requirement dictated by the liberal reward principle, which prescribes the equal treatment of individuals with the same circumstances.

Furthermore, Property 3 states that the more disadvantaged is the type, the more the social welfare will be sensitive to inequality of that tax burden among the individuals of that type. Thus, it introduce a diminishing sensitivity to horizontal inequity. The social evaluation of a tax-system increases more the more disadvantaged is the type within which the progressive transfer of income change takes place.

Based on the properties introduced above, we now identify the following families of social evaluation functions:

- $\mathbf{W}_{2}$ is the class of social evaluation functions constructed as in (1) and with social weight functions satisfying Properties 0 and 2;

- $\mathbf{W}_{1,2}$ is the class of social evaluation functions constructed as in (1) and with social weight functions satisfying Properties 0, 1 and 2;

- $\mathbf{W}_{2,3}$ is the class of social evaluation functions constructed as in (1) and with social weight functions satisfying Properties 0,2 and 3 . 


\subsection{Results}

We now turn to identify a range of conditions to be satisfied for ensuring the dominance of one tax system (tax reform) over the other in terms of opportunity egalitarian social welfare, for the different families of SEFs described above.

Although tax-reform and tax system evaluations usually assume the same initial distribution, here we provide more general results that also hold in the case of comparisons based on different pretax or pre-reform distributions. For each proposition we then provide a corollary which expresses the condition for the special case in which we compare two alternative tax systems applied to the same pre-tax distribution.

Beginning with the SWF of the type $\mathbf{W}_{2}$ the following result holds.

Proposition 1 Consider two alternative tax systems $\tau_{A}$ and $\tau_{B}$. For any pair of distributions $(F, \Omega)$ and $\left(G, \Omega^{\prime}\right) \in D, W\left(F, \Omega, \tau_{A}\right) \geq W\left(G, \Omega^{\prime}, \tau_{B}\right), \forall W \in \mathbf{W}_{2}$ if and only if

$$
\sum_{i=1}^{k} q_{i F} \delta_{i}^{\left(\tau_{A}\right)}(p) \geq \sum_{i=1}^{k} q_{i G} \delta_{i}^{\left(\tau_{B}\right)}(p), \forall k=1, \ldots, n, \forall p \in[0,1]
$$

Corollary 1 Consider any distribution $(F, \Omega) \in D$ and two alternative tax systems $\tau_{A}$ and $\tau_{B}$. $W\left(F, \Omega, \tau_{A}\right) \geq W\left(F, \Omega, \tau_{B}\right), \forall W \in \mathbf{W}_{2}$ if and only if

$$
\sum_{i=1}^{k} q_{i} \delta_{i}^{\left(\tau_{A}\right)}(p) \geq \sum_{i=1}^{k} q_{i} \delta_{i}^{\left(\tau_{B}\right)}(p), \forall k=1, \ldots, n, \forall p \in[0,1]
$$

The condition expressed in proposition 1 is a sequential inverse first order stochastic dominance. It has to be checked on each step of the sequential procedure, starting from the most disadvantaged type in the pre-tax distribution, then adding the second most disadvantaged, then the third, and so on. The condition to be satisfied at each stage is a first order dominance of the inverse distribution of income change generated by the tax-system $A$ over that generated by the tax-system $B$. In order to compare two tax-systems, a social planner endorsing preferences described by $\mathbf{W}_{2}$ would not only focus on the extent of tax-induced income change, but also on its vertical distributional impact, while it would be agnostic with respect to its horizontal distributional impact.

We now turn to the third class of SEF, that is $\mathbf{W}_{1,2}$.

Proposition 2 Consider two alternative tax systems $\tau_{A}$ and $\tau_{B}$. For any pair of distributions $(F, \Omega)$ and $\left(G, \Omega^{\prime}\right) \in D, W\left(F, \Omega, \tau_{A}\right) \geq W\left(G, \Omega^{\prime}, \tau_{B}\right), \forall W \in \mathbf{W}_{1,2}$ if and only if

$$
\sum_{i=1}^{k} q_{i F} \mu_{i}^{\left(\tau_{A}\right)} \geq \sum_{i=1}^{k} q_{i G} \mu_{i}^{\left(\tau_{B}\right)}, \forall k=1, \ldots, n
$$

where $\mu_{i}^{(\tau)}=\int_{0}^{1} \delta_{i}^{(\tau)}(p) d p$.

Corollary 2 Consider any distribution $(F, \Omega) \in D$ and two alternative tax systems $\tau_{A}$ and $\tau_{B}$. 
$W\left(F, \Omega, \tau_{A}\right) \geq W\left(F, \Omega, \tau_{B}\right), \forall W \in \mathbf{W}_{1,2}$ if and only if

$$
\sum_{i=1}^{k} q_{i} \mu_{i}^{\left(\tau_{A}\right)} \geq \sum_{i=1}^{k} q_{i} \mu_{i}^{\left(\tau_{B}\right)}, \forall k=1, \ldots, n
$$

where $\mu_{i}^{(\tau)}=\int_{0}^{1} \delta_{i}^{(\tau)}(p) d p$.

Proposition 2 is a sequential dominance of the weighted average changes in types. That is, take the worst type in the pre-tax distribution, check that the average income change of the individuals in that type is no lower under tax system $A$ than under tax system $B$; then add the second worst type and check for the same dominance; then add the third, and so on and repeat the check at every step. In this case, the dominance condition depends not only on the extent of the income change, but also on the incidence of taxes on the different types. According to this proposition, the final judgment on the comparison between two tax systems will also depend on its vertical (opportunity) distributional impact, while being neutral with respect to its horizontal distributional impact ${ }^{6}$

We then turn to the last family of SEW, that is $\mathbf{W}_{2,3}$.

Proposition 3 Consider two alternative tax systems $\tau_{A}$ and $\tau_{B}$. For any pair of distributions $(F, \Omega)$ and $\left(G, \Omega^{\prime}\right) \in D, W\left(F, \Omega, \tau_{A}\right) \geq W\left(G, \Omega^{\prime}, \tau_{B}\right), \forall W \in \mathbf{W}_{2,3}$ if and only if

$$
\sum_{i=1}^{k} q_{i F} \int_{0}^{p} \delta_{i}^{\left(\tau_{A}\right)}(s) d s \geq \sum_{i=1}^{k} q_{i G} \int_{0}^{p} \delta_{i}^{\left(\tau_{B}\right)}(s) d s, \forall k=1, \ldots, n, \forall p \in[0,1] .
$$

Corollary 3 Consider any distribution $(F, \Omega) \in D$ and two alternative tax systems $\tau_{A}$ and $\tau_{B}$. $W\left(F, \Omega, \tau_{A}\right) \geq W\left(F, \Omega, \tau_{B}\right), \forall W \in \mathbf{W}_{2,3}$ if and only if

$$
\sum_{i=1}^{k} q_{i} \int_{0}^{p} \delta_{i}^{\left(\tau_{A}\right)}(s) d s \geq \sum_{i=1}^{k} q_{i} \int_{0}^{p} \delta_{i}^{\left(\tau_{B}\right)}(s) d s, \forall k=1, \ldots, n, \forall p \in[0,1] .
$$

The condition characterized in Proposition 3 is a sequential second order inverse stochastic dominance, to be checked starting from the poorest type in the pre-tax distribution, then adding the second, then the third, and so on. The condition to be satisfied at each stage is that the cumulated sum of the individual income change, within each type, be no lower under tax $A$ than under tax $B$.

A point is in order here. In the case considered in Corollary 2, that is the case in which we compare tax systems imposed on the same pre-tax distribution, comparing the income changes induced by the two fiscal systems is equivalent to compare the respective post-tax income distributions, where types are ordered according to their rank in the pre-tax distribution. More precisely, the condition expressed in terms of income changes can equivalently be expressed in terms of post-tax incomes: that is, $\left[\sum_{i=1}^{k} q_{i} \mu_{i}^{\left(\tau_{A}\right)} \geq \sum_{i=1}^{k} q_{i} \mu_{i}^{\left(\tau_{B}\right)}, \forall k=1, \ldots, n\right]$ is equivalent to

\footnotetext{
${ }^{6}$ In the case of comparisons of tax systems applied to the same pre-tax distribution, the condition characterized in Proposition 2 may be also interpreted in terms of Type Opportunity Growth Incidence Curve (OGIC) dominance introduced by Peragine et al. (2014). In fact, the dominance condition contained in Corollary 2 is equivalent to the cumulated type OGIC dominance. Therefore, this proposition provides a normative justification for the use of the type OGIC in ranking two tax regimes. See also Palmisano ans Peragine (2014).
} 
$\left[\sum_{i=1}^{k} q_{i} \mu\left(y_{\tau_{A}}\right) \geq \sum_{i=1}^{k} q_{i} \mu_{i}\left(y_{\tau B}\right), \forall k=1, \ldots, n\right]$, where, with obvious notation, $\mu_{i}\left(y_{\tau_{A}}\right)$ represents the average income of type $i$ after $\operatorname{tax} \tau_{A}$

Analogous equivalences however do not hold for the cases of Corollary 1 and Corollary 3 , since within each type individuals are ordered anonymously on the basis of their income change, hence the dominance based on income changes is not equivalent to the dominance based on post tax incomes.

\subsection{Aggregate indexes}

In this section we introduce two families of aggregate measures that, on the base of the dominance conditions discussed above, allow for the assessment of the opportunity-distributional impact of a tax-reform, namely opportunity-sensitive vertical and horizontal incidence. These measures may be particularly helpful when the tax-systems being compared cannot be order through the partial ranking criteria listed above.

The first family of measures we wish to propose is aimed at disentangling and capturing the opportunity vertical equity of a tax regime, assuming neutrality with respect to horizontal equity. These measure can be used to evaluate different regimes on the base of their ability to favor the income change of the most disadvantaged individuals as compared to those most advantaged. This family can be defined as follows:

$$
O V E=\frac{\sum_{i=1}^{n} q_{i} v_{i} \mu_{i}^{(\tau)}(1)}{\sum_{i=1}^{n} q_{i} v_{i}}-\bar{W}^{*}
$$

Here $\bar{W}^{*}=\sum_{i=1}^{n} q_{i} \mu_{i}^{(\tau)}$ is the overall income change and can be interpreted as the income change every type would experience in case of proportional taxation. Eq. (8) represents a general family of aggregate measures and specific scalar measures can be obtained from it by simply choosing the proper functional form for the weighting function $v_{i}$, consistent with the requirement that $v_{i} \geq v_{i+1}$. Hence, $O V E$ represents a measure of the incidence of a tax-system in alleviating (worsening) economic disparities among individuals of different types. This index is equal to 0 in case of proportionality; it is positive in case of opportunity-progressivity and negative in case of opportunity regressivity.

The second family of measures we propose aims at isolating and quantifying the opportunity horizontal inequality component of a tax regime, assuming neutrality with respect to vertical inequality. This family is given by the following expression:

$$
O H I=\bar{W}^{*}-\sum_{i=1}^{n} q_{i} \int_{0}^{1} v(p) \delta_{i}^{(\tau)}(p) d p .
$$

Here $v(p)$ satisfies the following normalization condition: $\int_{0}^{1} v(p) d p=1$. In this case $\bar{W}^{*}=$ $\sum_{i=1}^{n} q_{i} \mu_{i}^{(\tau)}$ is interpreted slightly different from eq. (8): it represents the overall income change that would have resulted in the presence of a horizontal equal taxation. This index is equal to 0 in case of horizontal equity; it is positive if the tax reform is affected by horizontal inequality. Also in this case, specific measures of horizontal inequality can be obtained by specifying the functional form of the social weight $v(p)$.

It is worth noticing again that, with the exception of Peragine (2004), the existing literature does not provide other tools that enable to evaluate the distributional implications of a fiscal regime 
from the EOp perspective. However, while the indexes of opportunity redistribution and horizontal inequity introduced by Peragine (2004) are informative only when we compare tax systems applied on the same pre-tax distribution, our indexes do not suffer from this restriction.

\section{Income tax in Romania: a reform's microsimulation}

In this section we simulate a reform of the income tax in Romania - from the current flat tax rate to a more progressive income tax - and we assess the distributional impact of such reform adopting the model developed before.

\subsection{Personal income tax in Romania}

Before 2005 a progressive income taxation system was in place in Romania. It was based on a tax allowance (210 Romanian Lei, increasing by $50 \%$ for each additional dependent) and five tax rates ranging from $18 \%$ to $40 \%$. The personal income tax in Romania was reformed in 2005 with the main objectives of stimulating economic growth and reducing tax evasion and avoidance. Today the personal income tax is based on a $16 \%$ flat tax rate 7 All individuals that earn non exempted income pay the personal income tax. The tax base is obtained subtracting a tax allowance and other minor deductions from gross income minus social contributions 8

The introduction of a flat tax rate was associated with good performance in terms of tax revenues mainly due to an increase in the VAT revenue. However, the expected positive effects in terms of employment and growth have been rather weak according to what suggested by Schiau and Moga (2009). The redistributive effects of the reform have been very regressive, with the top quantiles gaining disproportionally more than poorer households: according to Eurostat inequality in Romania increased after the reform and was the highest in EU27 in 2007. Not surprisingly in a recently contribution Voinea and Mihaescu (2009) have suggested: "to replace the flat tax by a progressive tax, with two or three brackets, with large differences between them." (Voinea and Mihaescu 2009, p. 39). Although the main reason to reform the tax is redistributive in terms of income, we consider interesting to evaluate the effect of such a reform also in the space of opportunities. Thus, in the rest of the paper, we take the fiscal system in place in Romania in 2012 as the baseline scenario and we assess the distributive effect of a fiscal reform inspired by Voinea and Mihaescu (2009)' proposal, in the space of opportunity.

The reform proposal is based on four income brackets obtained updating those of the tax reform in place before 2005 . The tax rates are: $10 \%$ for taxable income up to 400 Lei, $15 \%$ for additional income up to 900 Lei and below 1,500 Lei, 20\% above 1,500 and below 2200 Lei, and $30 \%$ above this threshold. The reform guarantees the same income tax revenue for the state and the majority of income earners gain from it: the amount due is reduced for the bottom $80 \%$ of the tax payers (about 19 Lei less).

\footnotetext{
${ }^{7}$ A complete description of the Romanian fiscal system and of the characteristics simulated in EUROMOD can be found in Stroe et. al (2014). We consider only the personal income tax which is the only policy involved in the proposed reform.

${ }^{8}$ All incomes are expressed in monthly 2012 Lei. For pensioners the tax allowance has a maximum of 1000 Lei per month. Employees who have a monthly gross wage under or equal to 3000 Lei gets a tax allowance $(t a)$ of 250 Lei increased by 100 Lei fro each dependent (maximum tax allowance 650). The deduction is applied only on wages and only at the main job or activity. If the gross wage is between 1001 and 3000 Lei, the personal deduction is decreasing with income and its amount is established by applying the following formula: $t a \times\left(1-\frac{(\text { wage }-1000)}{2000}\right)$.
} 


\subsection{Data and methods}

The analysis is developed through EUROMOD microsimulation, using the Romanian Survey on Income and Living Conditions, Romanian implementation of the European Union Statistics on Income and Living Conditions (EU-SILC) collected in 2011. Because EUROMOD is based on different waves of EU-SILC, the original 2011 data for Romania have been updated, cleaned, imputed, and modified to meet all EUROMOD's requirements.

With EUROMOD we simulate two income distributions: i) the Romanian income distribution in 2012 (fiscal system in place in 2012), ii) a simulated hypothetical distribution for 2012 in which the flat rate personal income tax is replaced with a progressive tax based on four tax rates: $10 \%$, $15 \%, 20 \%, 30 \%$. The EU-SILC sample is representative of the Romanian population and has been obtained applying a two-stage probability sampling of housing units. Income information refers to incomes earned in 2010. The sample is made of 17,941 individuals divided into 7,675 households.

As reported above, in order to evaluate the effect of the reform in terms of equality of opportunity, we exploit the special module on Intergenerational Transmission of Disadvantages, containing information on socioeconomic background characteristics that can be used to define circumstances. We restrict the sample to individuals with non-negative disposable household incomes, aged between 25 and 65 . The unit of observation is the household, defined as all persons sharing the same dwelling. The variable of analysis is the household equivalent income, expressed in terms of 2012 euro. Household equivalent income is obtained dividing total income by the square root of the number of the household components.

We use two circumstance variables to define the types: parental education and parental occupation when the respondent was between 12 and 16 years old. Parental education is defined as the highest level attained by either of the parents and is categorized in three groups: low education when at most only one of the two parents attained elementary education, medium education when both parents had elementary education, high education when at least one parent had secondary or higher education. Parental occupation status is based on the highest ISCO 88 occupation status of the parents, grouped into four categories: highly skilled non-manual (ISCO between 11 and 34), lower-skill non-manual (41-52), skilled manual (61-83), and elementary occupation (91-93). The total population is thus partitioned into 12 types. This number is the result of a trade-off between the detail of information and the statistical reliability of the estimates. We consider only 12 types in order to have sufficient observations within each type to obtain statistically reliable estimates of our measures. Each type is then partitioned into 4 quantiles according to the income change experienced from before to after tax. Again, 4 is the maximum number of quantiles that allows us to have groups whit a sufficient sample size for the bootstrapping procedure.

Thus, when we analyze the impact of the reform in the space of outcome, we consider the entire sample of individuals with non-negative disposable household income aged between 25 and 65 . When we extend the analysis to the space of opportunity, instead, we need to drop individuals with missing information on the characteristics described above; in order to avoid the effect of outliers, we also drop individuals with 0 level of income. All our estimates are computed using sample weights.

Standard errors and $95 \%$ nonparametric percentile confidence intervals for all our estimates are obtained with 2,000 bootstrap replicates of each statistic (Davison and Hinkley, 1997). We assume that the income distributions observed before and after taxes, $y^{0}, y^{1}$ are independent and identically distributed observations of the unknown probability distributions $F\left(y^{0}\right), F\left(y^{1}\right) . \gamma$ is the statistic of interest and its standard error is: $\sigma\left(F\left(y^{0}\right), F\left(y^{1}\right)\right)=\sqrt{\operatorname{Var} \hat{\gamma}\left(y^{0}, y^{1}\right)}$. Our bootstrap estimate of 
the standard error is $\hat{\sigma}=\sigma\left(\hat{F}\left(y^{0}\right), \hat{F}\left(y^{1}\right)\right.$, where $\hat{F}\left(y^{0}\right), \hat{F}\left(y^{1}\right)$ are the empirical distributions observed. The $95 \%$ confidence interval were obtained resampling $B=2,000$ ordinary non parametric bootstrap replications of the two distribution $y_{0}^{*}, y_{1}^{*}$. The standard error of parameter $\hat{\gamma}$ is obtained as: $\hat{\sigma}_{B}=\sqrt{\sum_{b=1}^{B}\left\{\hat{\gamma}^{*}(b)-\hat{\gamma}(.)\right\}^{2} /(B-1)}$, where $\hat{\gamma}()=.\frac{\sum_{b=1}^{B} \gamma^{*}(b)}{B}$. We know that $\hat{\sigma}_{B} \rightarrow \hat{\sigma}$ when $B \rightarrow \infty$ and, under the assumption that $\gamma$ is approximately normally distributed, we calculate confidence intervals: $\hat{\gamma}=\hat{\gamma} \pm z_{1-\alpha / 2} \hat{\sigma}_{B}$. We are aware that the quality of our estimates depends on strong assumptions. However, as will become clear in the discussion of our results, the ranking of the two tax systems appears rather reliable for the illustrative purpose of this analysis.

Table 1 reports the list of types together with their population shares, the average of equivalent gross incomes and the average of net equivalent incomes in both the baseline and the reformed scenario. Types are ranked according to their average gross equivalent income. Rankings seem to be driven by the level of parental education of the household head ${ }^{9}$ In particular, all types with high parental education are the highest-ranked before and after tax, in both the actual tax system and the simulated reform.

Table 1: Descriptive Statistics.

\begin{tabular}{cccccccc}
\hline type & par. occupation & par. educ. & size & pop. share & $\mu_{2012}^{G R S S}$ & $\mu_{2012}^{N E T}$ & $\mu_{R E F O R M}^{N E T}$ \\
\hline \hline 1 & Skilled manual & Low & 94 & 0.0111 & 985.93 & 801.51 & 808.55 \\
2 & Highly skilled non-manual & Low & 882 & 0.1065 & 1113.82 & 899.85 & 905.07 \\
3 & Elementary occupation & Medium & 515 & 0.0604 & 1240.30 & 983.22 & 988.65 \\
4 & Skilled manual & Medium & 2230 & 0.2610 & 1244.47 & 986.84 & 994.65 \\
5 & Highly skilled non-manual & Medium & 2536 & 0.2844 & 1283.98 & 1013.17 & 1019.09 \\
6 & Elementary occupation & Low & 553 & 0.0536 & 1311.77 & 1060.34 & 1056.40 \\
7 & Lower skilled non-manual & Low & 12 & 0.0013 & 1324.55 & 1147.68 & 1152.22 \\
8 & Lower skilled non-manual & Medium & 321 & 0.0415 & 1568.19 & 1226.38 & 1225.78 \\
9 & Skilled manual & High & 156 & 0.0228 & 1827.85 & 1406.58 & 1414.63 \\
10 & Lower skilled non-manual & High & 464 & 0.0652 & 2027.40 & 1557.00 & 1543.32 \\
11 & Elementary occupation & High & 136 & 0.0209 & 2307.51 & 1699.40 & 1641.52 \\
12 & Highly skilled non-manual & High & 512 & 0.0713 & 2355.92 & 1756.47 & 1713.32 \\
\hline \multicolumn{7}{c}{ source: authors' elaboration based on EUSILC 2011 $\mathcal{E}$ EUROMOD G1.0 }
\end{tabular}

\subsection{Redistributive effects}

We start our analysis by providing an assessment of the distributional effects of the reform in terms of household disposable equivalent income, considering, as already explained above, the whole and representative population. Table 2 reports the Gini and Mean Logarithmic Deviation (MLD) indices of income inequality and the average equivalent income of three distributions: the gross income distribution, the net income distribution with the fiscal system in force, the net income distribution with the reform. Both systems appear to be progressive: inequality from gross to net

\footnotetext{
${ }^{9}$ See Machin and Vignoles (2004) on the connections between education, income and the extent of intergenerational mobility in economic status and Andren et al. (2005) on the relevance of education in Romania.
} 
Figure 1: Distributive effect of the reform: difference between Growth Incidence Curves

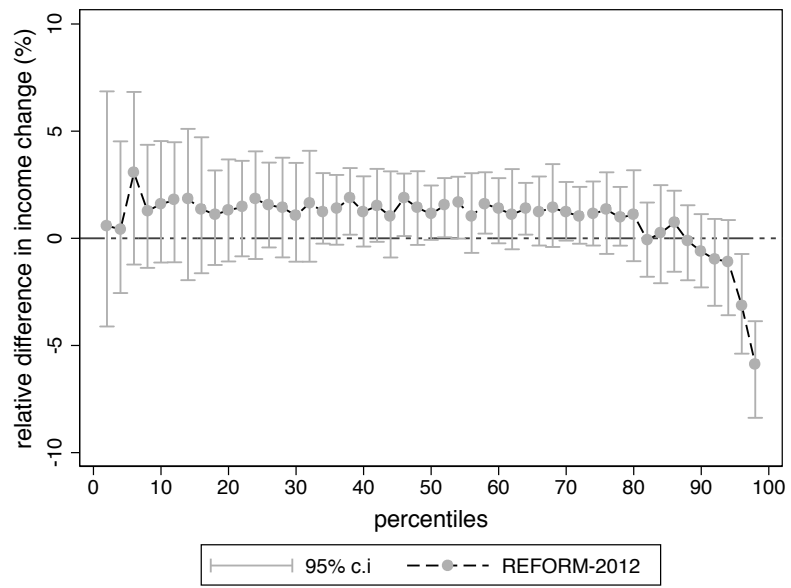

source: authors' elaboration based on EUSILC 2011 \& EUROMOD G1.0

income always decreases. However, the reform is clearly more redistributive than the fiscal system in place in 2012, in particular the difference between the Gini index of the post-tax income distribution with the actual tax system and the Gini index of the of the post-reform distribution is statistically significant at the $95 \%$ level. The disaggregated effect of moving from the baseline scenario to the reformed fiscal system is represented by the difference between the Growth Incidence Curve (GIC, Ravallion and Chen 2003), generated by the actual fiscal regime, and the GIC that would be generated by the reform and is reported in Figure 1. The GIC plots the quantile specific relative income change from the pre-tax to the post-tax distribution. Given that apart from the personal income tax all the other taxes and transfers are unchanged, the change in equivalent disposable income under the two scenarios is low and significantly different from zero only for the very richest quantiles. The absence of dominance is clearly due to the fact that we are comparing the actual system with an equal-levy reform. However, because of the progressivity of the reform, the point estimate of the quantile specific changes are positive for the bottom $80 \%$ of the distribution and monotonically decreasing with the rank.

Table 2: Distributive effect of the tax system in force and the hypothetical reform.

\begin{tabular}{|c|ccc|}
\hline & Gross 2012 & Net 2012 & Net Reform \\
\hline \hline Gini & $0.3712(0.3674,0.3749)$ & $0.3247(0.3211,0.3281)$ & $0.3168(0.3135,0.3199)$ \\
MLD & $0.2748(0.2675,0.2825)$ & $0.1928(0.1882,0.1968)$ & $0.1847(0.1808,0.1896)$ \\
avg. eq. income & $1,265.71(1252,32,1279.40)$ & $1,030.32(1021.38,1039.47)$ & $1,030.98(1022.30,1040.02)$ \\
\hline
\end{tabular}

source: authors' elaboration based on EUSILC 2011 \& EUROMOD G1.0.

We now shift our focus to the space of opportunities. Before discussing our results, let us clarify two methodological choices. First, $\delta^{2012}(p)$ refers to the change from gross to net income with 
Figure 2: Test proposition 1.
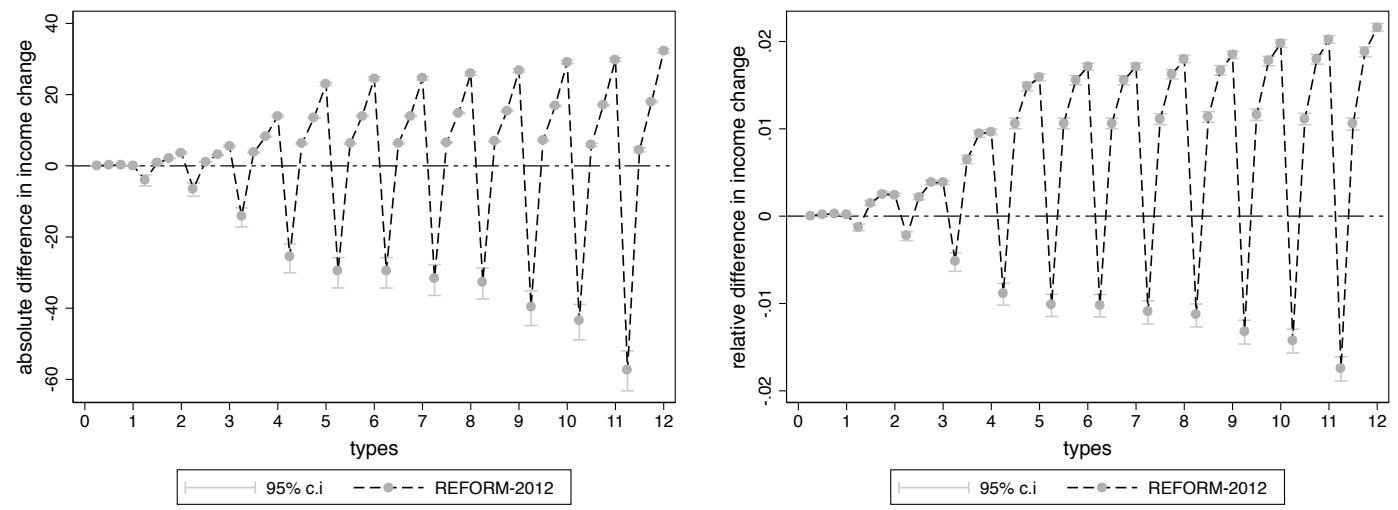

source: authors' elaboration based on EUSILC 2011 \& EUROMOD G1.0

the tax system in force in 2012, while $\delta^{R}(p)$ refers to the change from gross to net income with the reform. Second, the analysis is performed by considering both absolute and relative income changes.

We start with proposition 1, which incorporates aversion to inequality between types but remains agnostic with respect to inequality within types. This proposition must be checked sequentially. First, within each type, we order individuals increasingly on the base of the income change experienced. We then divide each type distribution into four quantiles $\pi=(.25,0.5,0.75,1)$. We estimate the following:

$$
\sum_{i=1}^{k} q_{i} \delta_{i}^{(R)}(\pi)-\sum_{i=1}^{k} q_{i} \delta_{i}^{(2012)}(\pi) \geq 0, \forall k=1, \ldots, 12, \forall \pi \in[0,1]
$$

The first step consists of checking the dominance of the income change of each $\pi$ quantile for the individuals in the poorest type 1 between pre-tax and post-tax income generated under the reform, with respect to the same change generated by the system in place. The second steps, instead, requires to sum, quantile by quantile the income change of type 1 and 2 and, again, to check the dominance between the tax system hypothesized and that in force, weighted by the respective type population share, at each quantile $\pi$. We repeat the same procedure for the ten remaining steps, by adding less poor types at each step, up to type 12 . Figure 2 reports the result of this check at each quantile and type, for both the absolute (left panel) and relative (right panel) change. Proposition 1 is satisfied if we find a statistically significant positive value for this difference at all steps. This is again not the case, in fact, as we can observe from the figure, at each sequential aggregation, the dominance is positive for all except the poorest quantile of income change. This implies that, with this kind of reform, a social planner would tax more the most taxed individuals within each type, as compared to the baseline scenario, while he would tax less the three least taxed individuals $\sqrt{10}$ Hence, although most of the distribution seems to benefit from the reform, we cannot safely rank the two tax systems when the social planner is in favor of opportunity vertical equity but agnostic with respect to opportunity horizontal equity.

\footnotetext{
${ }^{10}$ The $95 \%$ bootstrapped confidence intervals for this test are reported in Table 4 and 5 of the statistical appendix.
} 
Figure 3: Test proposition 2
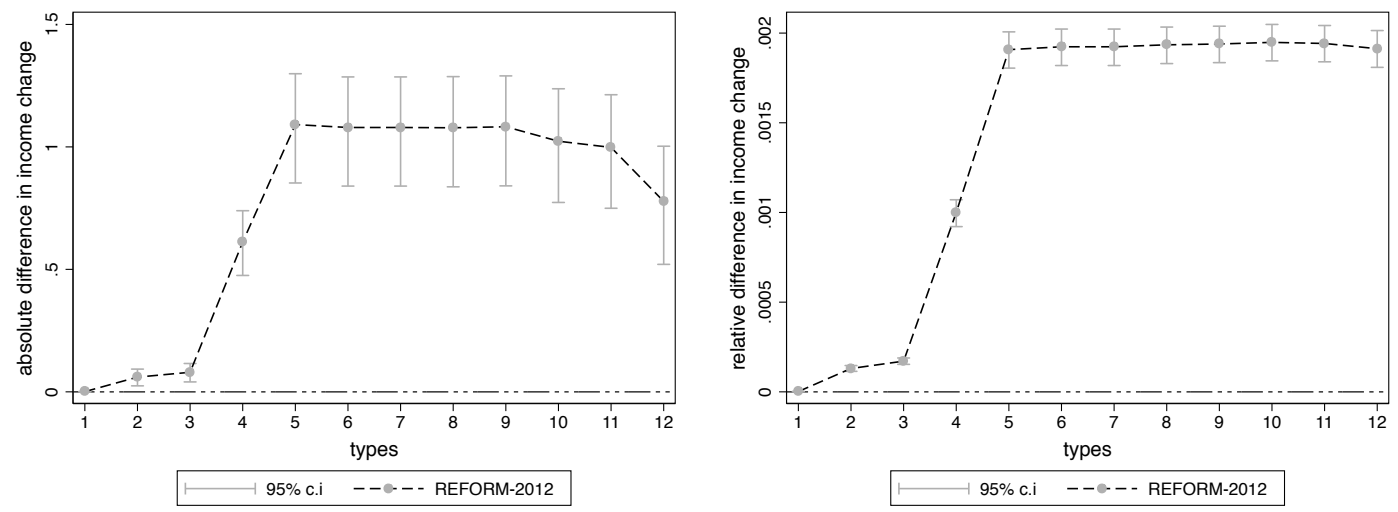

source: authors' elaboration based on EUSILC 2011 \& EUROMOD G1.0

We now illustrate the result of this normative comparison by imposing more restrictions on the social evaluation function. That is we assume that a social planner is averse to inequality between type but neutral with respect to inequality within type. Hence we apply the test proposed in proposition 2, which is also checked sequentially, starting from the worst type up to the richest type. We estimate the following:

$$
\sum_{i=1}^{k} q_{i} \mu_{i}^{(R)}-\sum_{i=1}^{k} q_{i} \mu_{i}^{(2012)} \geq 0, \forall k=1, \ldots, 12
$$

That is, at the firs step we start form type 1 and we check the dominance of the average change from pre-tax to post-tax income, experienced by its individuals and weighted by its population share under the reform, with respect to the same change experienced under the tax system in force. At the second step, we add the average change experienced by the individuals of type 2, weighted by the population share of this type, and we check again the positivity of this dominance. We repeat the same procedure for the remaining 10 step. The test is represented in Figure 3, which plots against each type the cumulated weighted average income change, both in absolute (left panel) and relative (right panel) terms. Proposition 2 is satisfied if we find a statistically significant positive value for this difference at all steps. Note that, the test in proposition 2 is a sequential test for the difference in partial means of income change, weighted by the population share of the first $i-t h$ types 11 This test finally allows us to rank the two tax systems: the reform dominates the actual Rumanian tax-regime according to the family of social evaluation functions that are in favor of opportunity vertical equity, but neutral to opportunity horizontal equity. In fact, Figure 3 shows that the coordinates of the curves are always positive.

Last, we provide a comparison between the two tax systems when horizontal equity is also a matter of concern for the social planner. Thus, we apply the test presented in proposition 3. As done in proposition 1, we partition each the type-specific distribution of income change into four quantiles of income change: $\pi=(0.25,0.5,0.75,1)$. We then estimate the following:

\footnotetext{
${ }^{11}$ The $95 \%$ bootstrapped confidence intervals for this test are reported in Table 6 and 7 of the statistical appendix.
} 
Figure 4: Test proposition 3
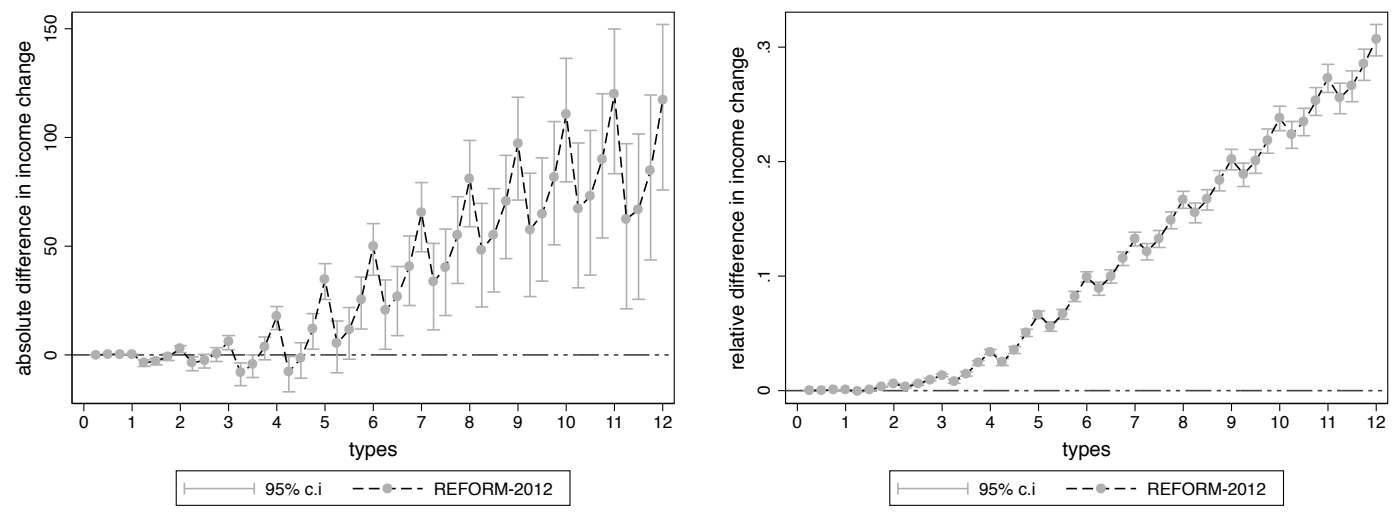

source: authors' elaboration based on EUSILC 2011 \& EUROMOD G1.0

$$
\sum_{i=1}^{k} q_{i} \int_{0}^{\pi} \delta_{i}^{(R)}(q) d q-\sum_{i=1}^{k} q_{i} \int_{0}^{\pi} \delta_{i}^{(2012)}(q) d q \geq 0, \forall k=1, \ldots, 12, \forall p \in[0,1] .
$$

We start from the poorest type $i=1$ and, at each cumulated quantile $\pi=0.25,0.5,0.75,1$, we have to check the dominance of the individual income change, weighted by the population share of type 1 , generated by the reform with respect to the change generated by the actual system. The second steps, instead, requires to sum, quantile by quantile, the income change of type 1 and 2 and, again, to check the positivity of this dominance, weighted by the respective type population share, at each cumulated quantile $\pi$. We repeat the same procedure for the ten remaining steps, by adding the less poor type at each step, up to type 12 .

Figure 4 reports the result of this check at each cumulated quantile and type, for both the absolute (left panel) and relative (right panel) change. Proposition 3 is satisfied if we find a statistically significant positive value for this difference at all steps. Unfortunately, when the social planner endorse concerns for both vertical and horizontal equity, it is not possible to establish a clear dominance between the fiscal regime in force and the tax reform hypothesized. As it is possible to grasp from the figure, this difference is negative for some of the quantiles of income change within the poorest types 12

In sum, although in most cases the positivity of the cumulated income change seems to support the power of the reform against the actual tax system, we cannot safely rank the two tax systems when the social planner is in favor of both opportunity vertical and horizontal equity.

We conclude our analysis with the assessment of the reform and the comparison with respect to the system in place, by computing the aggregate indexes described in section 2.4. The value of these indexes, for (R) and (2012) and their difference are reported in Table 3 both for absolute and relative income changes. The first index we consider is $O V E$, which captures the vertical equity a tax system in the space of opportunities ${ }^{13}$ It comes out that $O V E$ is positive for $(R)$ and (2012),

\footnotetext{
${ }^{12}$ The bootstrapped $95 \%$ confidence intervals of the test are reported in Table 8 and 9 of the statistical appendix.

${ }^{13}$ We use the following wights: $v_{i}=\frac{i}{n(n+1) \frac{1}{2}}$
} 
Table 3: Aggregate indexes.

\begin{tabular}{rrrrrrrrrr}
\hline & 2012 & 0.95 c.i. & 0.95 c.i. & REFORM & 0.95 c.i. & 0.95 c.i. & difference & 0.95 c.i. & 0.95 c.i. \\
\hline OVE (absolute income) & 40.1677 & 36.1126 & 44.0852 & 45.1284 & 40.1442 & 49.7587 & 4.9607 & 4.0487 & 5.8528 \\
OVE (relative income) & 0.0119 & 0.0098 & 0.0139 & 0.0139 & 0.0117 & 0.0160 & 0.0020 & 0.0017 & 0.0022 \\
OHI (absolute income) & 116.3856 & 110.7707 & 122.8405 & 122.6192 & 115.5343 & 130.7570 & -6.2336 & -8.2003 & -4.3324 \\
OHI (relative income) & 0.0655 & 0.0635 & 0.0674 & 0.0677 & 0.0655 & 0.0697 & -0.0021 & -0.0028 & -0.0015 \\
\hline
\end{tabular}

source: authors' elaboration based on EUSILC $2011 \&$ EUROMOD G1.0

implying that both systems are alleviating the disparities between the socio-economic groups we are considering in these illustration. However, the progressivity of the reform tends to be higher than that of the actual system in place. This result supports the evidence that the reform is more desirable than the actual system in place, when the social planner is averse to inequality between types, which emerged from the test of proposition 2. The second index we consider is $O H I$, which captures the horizontal equity of a tax reform in the space of opportunity ${ }^{14}$ The positivity of $O H I$ for the two systems compared suggests that they both contain a certain degree of horizontal inequity. However, the higher value of $O H I$ for (2012) implies that the reform is again more socially desirable than the fiscal system in force, when horizontal inequality matters.

\section{Conclusions}

In this paper, we have investigated the possibility of developing a model for the normative assessment of tax systems and reforms, that is consistent with the emerging theory on Equality of Opportunity. In so doing, we have argued that the opportunity egalitarian theory may provide an alternative key to reinterpret the definition of a 'just taxation'. To this aim, we have proposed a reinterpretation of the classical vertical and horizontal equity principles, under the light of the opportunity egalitarian principles. In particular, vertical equity has been formulated by looking at individuals characterized by different circumstances, hence having access to different set of opportunities. Whereas, horizontal equity has been formulated with reference to individuals characterized by same circumstances. We have framed these reinterpretations by means of an axiomatic procedure and, through it, we have obtained a set of dominance conditions that can be used to rank tax regimes or to compare the effects of different tax reforms. On the base of these dominance criteria, we have then suggested two aggregated indexes to measure the extent of the opportunity vertical and horizontal equity.

Finally, we have adopted our framework to evaluate the effect of an hypothetical tax reform in Romania, a country characterized by a particular tax history. The reform hypothesized is based on four income brackets, with tax rates ranging from $15 \%$ to $30 \%$. We have compared this tax structure with the actual Romanian tax regime, based on a $16 \%$ flat tax rate. Our results, obtained through a microsimulation analysis on the Romanian implementation of the EU-SILC, suggest that such a reform would improve social welfare not only according to the standard practice of looking at the outcome distribution before and after tax but, most importantly, also when an opportunity egalitarian perspective is endorsed.

\footnotetext{
${ }^{14}$ We use the following weights: $v(p)=\frac{p}{m(m+1) \frac{1}{2}}$, where $m$ is the number of quantiles.
} 


\section{References}

1. Aaberge, R. (2001). Axiomatic characterization of the Gini coefficient and Lorenz curve orderings, Journal of Economic Theory, 101(1), 115-132.

2. Aaberge, R., Colombino, U. (2012). Accounting for family background when designing optimal income taxes: A microeconometric simulation analysis, Journal of Population Economics, 25(2), 741-761.

3. Aaberge, R., Mogstad, M., Peragine, V. (2011). Measuring long-term inequality of opportunity, Journal of Public Economics 95(3-4): 193-204.

4. Andren, D., Earle, J. S., Săpătoru, D. (2005). The wage effects of schooling under socialism and in transition: evidence from Romania, 1950-2000. Journal of Comparative Economics, $33(2), 300-323$.

5. Andreoli, F., Havnes, T., Lefranc, A. (2014). Equalization of opportunity: definitions, implementable conditions and application to early-childhood policy evaluation, paper presented at the 33rd IARIW Conference, Rotterdam, The Netherlands.

6. Bourguignon, F. (2011). Status quo in the welfare analysis of tax reforms, Review of Income and Wealth, 57(4), 603-621.

7. Cowell, F. (2000). The measurement of inequality, in A. Atkinson and F. Bourguignon (eds), Handbook of Income Distribution, Elsevier, Amsterdam, 87-165.

8. Davison, A.C. and Hinkley, D.V. (1997) Bootstrap methods and their application, Chapter 5. Cambridge University Press.

9. Duclos, J. Y., Lambert, P. J. (2000). A normative and statistical approach to measuring classical horizontal inequity, Canadian Journal of Economics/Revue canadienne d'économique, $33(1), 87-113$.

10. Ferreira F., Peragine V. Equality of opportunity, in M. Adler and M. Fleurbaey (eds), Handbook of Well Being and Public Policy, Oxford University Press, (forthcoming).

11. Fleurbaey, M. (2008). Fairness, responsibility and welfare. 1st Edition. Oxford University Press.

12. Fleurbaey, M., Peragine, V. (2013). Ex ante versus ex post equality of opportunity, Economica $8(317), 118-30$.

13. Jacquet, L., Van de gaer, D. (2011). A comparison of optimal tax policies when compensation or responsibility matter. Journal of Public Economics, 95(11), 1248-1262.

14. Jenkins, S., Lambert, P.J. (1999). Horizontal inequity measurement: a basic reassessment, in Silber, J. (Ed.) Handbook of Income Inequality Measurement, Kluwer Academic Publishers, $535-556$.

15. Lambert, P.J. (2001). The distribution and reditribution of income. Manchester University Press. 
16. Lambert, P.J. (2004). Income taxation and equity, Baltic Journal of Economics, 4(2), 39-54.

17. Lefranc, A., Pistolesi, N., Trannoy, A. (2009). Equality of opportunity and luck: definitions and testable conditions, with an application to income in France, Journal of Public Economics 93(11-12), 1189-1207.

18. Machin, S., Vignoles, A. (2004). Educational inequality: the widening socioeconomic gap, Fiscal Studies, 25(2), 107-128.

19. Mirrlees, J. (1971). An exploration in the theory of optimal income taxation, Review of Economic Studies, 38, 175-208.

20. Musgrave, R. (1959). The theory of public finance: a study in public economy, McGraw-Hill, New York.

21. Palmisano, F. (2011). Mobility and long term equality of opportunity, Research on Economic Inequality, 19, 51-75.

22. Palmisano, F, Peragine, V. (2014). The distributional incidence of growth: a social welfare approach, Review of Income and Wealth, DOI: 10.1111/roiw.12109.

23. Peragine, V. (2002). Opportunity egalitarianism and income inequality: the rank-dependent approach, Mathematical Social Sciences 44, 45-64.

24. Peragine, V. (2004). Measuring and implementing equality of opportunity for income, Social Choice and Welfare, 22(1), 187-210.

25. Peragine, V., Palmisano, F., Brunori, P. (2014). Economic growth and equality of opportunity, The World Bank Economic Review, 28(2), 247-281.

26. Ramos, X., Van de gaer, D. (2012). Empirical approaches to inequality of opportunity: principles, measures and evidences, Working Paper 259, ECINEQ.

27. Ravallion, M., Chen, S. (2003). Measuring pro-poor growth, Economics Letters 78(1), 93-99.

28. Roemer, J.E. (1998). Equality of opportunity. Cambridge, MA: Harvard University Press.

29. Roemer, J.E., Aaberge, R., Colombino, U., Fritzell, J., Jenkins, S., Lefranc, A., et al. (2003). To what extent do fiscal systems equalize opportunities for income acquisition among citizens?, Journal of Public Economics 87, 539-65.

30. Roemer, J.E., Trannoy, A. (2013). Equality of opportunity, No. 1921. Cowles Foundation for Research in Economics, Yale University.

31. Schiau, L.L., Moga, A.C. (2009). The flat tax effects: theoretical and empirical evidences in western and eastern European countries, Annals of Faculty of Economics, University of Oradea, Faculty of Economics, 3(1), 343-348.

32. Schokkaert, E., Van de gaer, D., Vandenbroucke, F., Luttens, R. I. (2004). Responsibility sensitive egalitarianism and optimal linear income taxation, Mathematical Social Sciences, 48(2), 151-182. 
33. Stroe, C., Militaru, E., Avram, S., Cojanu, S. (2014) EUROMOD Country Report. Romania 2009-2013, http://www.iser.essex.ac.uk/research/euromod

34. Urban, I., Lambert, P.J. (2008). Redistribution, horizontal inequity, and reranking: how to measure them properly, Public Finance Review.

35. Van de gaer, D. 1993. Equality of opportunity and investment in human capital. Ph.D. Dissertation, Katholieke Universiteit Leuven.

36. Voinea, L., Mihaescu, F. (2009). The Impact of the flat tax reform on inequality: the case of Romania, Romanian Journal of Economic Forecasting 4, 19-41. 


\section{Appendix}

Before proving Proposition 1 we state the following Abel's Lemma ${ }^{15}$

Abel's Lemma. If $v_{1} \geq \ldots \geq v_{i} \geq \ldots \geq v_{n} \geq 0$, a sufficient condition for $\sum_{i=1}^{n} v_{i} w_{i} \geq 0$ is $\sum_{i=1}^{j} w_{i} \geq 0 \forall j=1, \ldots, n$. If $v_{1} \leq \ldots \leq v_{i} \leq \ldots \leq v_{n} \leq 0$, the same condition is sufficient for
$\sum_{i=1}^{n} v_{i} w_{i} \leq 0$.

\section{Proof of Proposition 1}

We now want to find a necessary and sufficient condition for

$$
\Delta W=\sum_{i=1}^{n} \int_{0}^{1} v_{i}(p)\left[q_{i F} \delta_{i}^{\left(\tau_{A}\right)}(p)-q_{i G} \delta_{i}^{\left(\tau_{B}\right)}(p)\right] d p \geq 0, \forall W \in \mathbf{W}_{2}
$$

Sufficiency can be shown as follows. First, reverse the order of integration and summation, such that

$$
\Delta W=\int_{0}^{1} \sum_{i=1}^{n} v_{i}(p)\left[q_{i F} \delta_{i}^{\left(\tau_{A}\right)}(p)-q_{i G} \delta_{i}^{\left(\tau_{B}\right)}(p)\right] d p \geq 0
$$

Letting $S_{i}(p)=q_{i F} \delta_{i}^{\left(\tau_{A}\right)}(p)-q_{i G} \delta_{i}^{\left(\tau_{B}\right)}(p)$ and rewriting (14):

$$
\Delta W=\int_{0}^{1} \sum_{i=1}^{n} v_{i}(p) S_{i}(p) d p \geq 0
$$

By property $2 v_{i}(p) \geq v_{i+1}(p) \geq 0, \forall i=1, \ldots, n-1$ and $\forall p \in[0,1]$, we can apply the Abel's Lemma and obtain that $\sum_{i=1}^{n} v_{i}(p) S_{i}(p) \geq 0$ if $\sum_{i=1}^{k} S_{i}(p) \geq 0, \forall k=1, \ldots, n$ and $\forall p \in[0,1]$. It follows that $\sum_{i=1}^{n} v_{i}(p) S_{i}(p) \geq 0, \forall p \in[0,1]$, implies that, integrating with respect to $p$, $\int_{0}^{1} \sum_{i=1}^{n} v_{i}(p) S_{i}(p) d p \geq 0$.

For the necessity, suppose for a contradiction that $\Delta W \geq 0, \forall W \in \mathbf{W}_{2}$, but there is a type $h \in\{1, \ldots, n\}$ and an interval $I \equiv[a, b] \subseteq[0,1]$ such that $\sum_{i=1}^{h} S_{i}(p)<0, \forall p \in I$. Now, applying Abel's Lemma, there exists a set of functions $\left\{v_{i}(p) \geq 0\right\}$, such that $\sum_{i=1}^{n} v_{i}(p) S_{i}(p)<0, \forall p \in I$. Writing $\sum_{i=1}^{n} v_{i}(p) S_{i}(p)=T(p), \Delta W$ reduces to $\int_{0}^{1} T(p) d p$, where $T(p)<0, \forall p \in I$. Selecting a set of function $T(p)$, such that $T(p) \longrightarrow 0, \forall p \in[0,1] \backslash I, \Delta W$ would reduce to $\int_{a}^{b} T(p) d p<0$, a contradiction. QED

\section{Proof of Proposition 2}

We want to find a necessary and sufficient condition for

$$
\Delta W=\sum_{i=1}^{n}\left(q_{i F} \int_{0}^{1} v_{i}\left(p_{t}\right) \delta_{i}^{\left(\tau_{A}\right)}\left(p_{t}\right)-q_{i G} \int_{0}^{1} v_{i}\left(p_{t}\right) \delta_{i}^{\left(\tau_{B}\right)}\left(p_{t}\right) d p\right) \geq 0, \forall W \in \mathbf{W}_{1,2}
$$

For the sufficiency, by property $1 v_{i}(p)=\beta_{i}, \forall p \in[0,1]$ and $\forall i=1,2, \ldots, n$, therefore we can write eq. (16) as follows:

$$
\Delta W=\sum_{i=1}^{n} \beta_{i}\left[q_{i F} \int_{0}^{1} \delta_{i}^{\left(\tau_{A}\right)}\left(p_{t}\right) d p-q_{i G} \int_{0}^{1} \delta_{i}^{\left(\tau_{B}\right)}\left(p_{t}\right) d p\right]=
$$

\footnotetext{
${ }^{15}$ See Jenkins and Lambert (1993) for a formal proof.
} 


$$
=\sum_{i=1}^{n} \beta_{i}\left[q_{i F} \mu_{i}^{\left(\tau_{A}\right)}-q_{i G} \mu_{i}^{\left(\tau_{B}\right)}\right] \geq 0 .
$$

Given that $v_{i}\left(p_{t}\right)=\beta_{i} \geq 0 \forall p_{t} \in[0,1]$ and $\forall i=1,2, \ldots, n$, and given that by property $2 \beta_{i} \geq \beta_{i+1}$, we can apply Abel's Lemma to obtain that $\Delta W \geq 0$ if $\sum_{i=1}^{j}\left(q_{i F} \mu_{i}^{\left(\tau_{A}\right)}-q_{i G} \mu_{i}^{\left(\tau_{B}\right)}\right) \geq 0, \forall j=1, \ldots, n$.

For the necessity, suppose that

$$
\Delta W=\sum_{i=1}^{n} \beta_{i}\left[q_{i F} \mu_{i}^{\left(\tau_{A}\right)}-q_{i G} \mu_{i}^{\left(\tau_{B}\right)}\right] \geq 0
$$

but $\exists k=1, \ldots, n$ such that $\sum_{j=1}^{k}\left(q_{j F} \mu_{j}^{\left(\tau_{A}\right)}-q_{j G} \mu_{j}^{\left(\tau_{B}\right)}\right)<0$. We can choose a set of numbers $\left\{\beta_{i}\right\}_{i=1, \ldots, n}$ such that $\beta_{i} \searrow 0, \forall i>k . \Delta W$ would reduce to $\sum_{j=1}^{k} \beta_{k}\left(q_{k F} \mu_{k}^{\left(\tau_{A}\right)}-q_{k G} \mu_{k}^{\left(\tau_{B}\right)}\right)<0$, a contradiction. QED

\section{Proof of Proposition 3}

We want to find a necessary and sufficient condition for

$$
\Delta W=\sum_{i=1}^{n} \int_{0}^{1} v_{i}(p)\left[q_{i F} \delta_{i}^{\left(\tau_{A}\right)}(p)-q_{i G} \delta_{i}^{\left(\tau_{B}\right)}(p)\right] d p \geq 0, \forall W \in \mathbf{W}_{2,3}
$$

Sufficiency can be shown as follows. First, letting $S_{i}(p)=q_{1 F} \delta_{i}^{(1)}(p)-q_{i G} \delta_{i}^{(2)}(p)$ and integrating by parts eq. (18)

$$
\Delta W=\sum_{i=1}^{n}\left[v_{i}(1) \int_{0}^{1} S_{i}(p) d p\right]-\sum_{i=1}^{n} \int_{0}^{1} v_{i}^{\prime}(p) \int_{0}^{p} S_{i}(q) d q d p
$$

reversing the order of integration and summation in the second part of eq. (19):

$$
\Delta W=\sum_{i=1}^{n}\left[v_{i}(1) \int_{0}^{1} S_{i}(p) d p\right]-\int_{0}^{1} \sum_{i=1}^{n} v_{i}^{\prime}(p) \int_{0}^{p} S_{i}(q) d q d p
$$

By property 3, we can apply Abel's Lemma to get that $\sum_{i=1}^{j} \int_{0}^{p} S_{i}(q) d q \geq 0, \forall_{j}=1, \ldots, n$ and $\forall p \in[0,1]$ implies $-\int_{0}^{1} \sum_{i=1}^{n} v_{i}^{\prime}(p) \int_{0}^{p} S_{i}(q) d q d p \geq 0$, but given property 2 , this also implies that $\sum_{i=1}^{n}\left[v_{i}(1) \int_{0}^{1} S_{i}(p) d p\right] \geq 0$, hence it is sufficient for $\Delta W \geq 0$.

For the necessity, by application of Abel's decomposition, write eq. (18) as follows:

$$
\Delta W=\sum_{i=1}^{n}\left[v_{i}(1) \int_{0}^{1} S_{i}(p) d p\right]+\int_{0}^{1} \varepsilon_{n}(p) \sum_{i=1}^{n} \int_{0}^{p} S_{i}(q) d q d p+\int_{0}^{1} \sum_{i=1}^{n-1} \omega_{i}(p) \sum_{j=1}^{i} \int_{0}^{p} S_{j}(q) d q d p
$$

with $\varepsilon_{n}(p)=-v_{n}^{\prime}(p) \forall p$ and $\omega_{i}(p)=-\left(v_{i}^{\prime}(p)-v_{i+1}^{\prime}(p)\right) \forall_{i}$ and $\forall p$. Now, suppose for a contradiction that $\Delta W \geq 0$, but $\exists h$ and interval $I \equiv[a, b] \subseteq[0,1]$ such that $\sum_{j=1}^{h} \int_{0}^{p} S_{j}(q) d q$ 
$<0, \forall p \in I$. Applying Lemma 1 in Chambaz and Maurin (1998), that there extists a set of nonnegative functions $\left\{\phi_{i}(p)\right\}_{i \in\{1, \ldots, n-1\}}$ such that $\sum_{i=1}^{n-1} \phi_{i}(p)\left(\sum_{j=1}^{i} \int_{0}^{p} S_{i}(q) d q\right)<0 \forall p \in I$. By Lemma 2 in Chambaz and Maurin (1998) there exists a set of non-negative functions $\tau(p)$ such that $\int_{0}^{1} \tau(p) \sum_{j=1}^{n} \phi_{i}(p) \sum_{i=1}^{j} \int_{0}^{p} S_{j}(q) d q d p<0$. Now, write $\tau(p) \phi_{i}(p)=\omega_{i}(p)$, given that $\tau(p) \phi_{i}(p) \geq$ $0, \omega_{i}(p)$ satisfies eq. (6) and (7). Hence, $\int_{0}^{1} \sum_{i=1}^{n-1} \omega_{i}(p)\left(\sum_{j=1}^{i} \int_{0}^{p} S_{j}(q) d q\right) \leq 0$. Applying again Lemma 2 and following a similar argument as above, we will have that $\int_{0}^{1} \varepsilon_{n}(p) \sum_{j=i}^{n} \int_{0}^{p} S_{j}(q) d p \leq$ 0 . Thus, it is possible to choose a combination of $v_{i}(1)$ and $\int_{0}^{1} S_{j}(p) d p$ to contradict eq.(18) QED. 
5 Statistical appendix 
Table 4: Bootstraped standard errors for proposition 1 with absolute income change

\begin{tabular}{|c|c|c|c|c|}
\hline & quartile & Reform-2012 & 0.95 c.i. & 0.95 c.i. \\
\hline \multirow{4}{*}{ type 1} & 1 & -0.01 & -0.01 & -0.01 \\
\hline & 2 & 0.18 & 0.18 & 0.18 \\
\hline & 3 & 0.10 & 0.10 & 0.10 \\
\hline & 4 & 0.04 & 0.04 & 0.04 \\
\hline \multirow{4}{*}{ type 2} & 1 & -3.93 & -5.61 & -2.57 \\
\hline & 2 & 0.74 & 0.65 & 0.83 \\
\hline & 3 & 2.05 & 1.97 & 2.14 \\
\hline & 4 & 3.66 & 3.43 & 3.95 \\
\hline \multirow{4}{*}{ type 3} & 1 & -6.47 & -8.50 & -4.81 \\
\hline & 2 & 1.14 & 1.03 & 1.26 \\
\hline & 3 & 3.05 & 2.96 & 3.15 \\
\hline & 4 & 5.50 & 5.24 & 5.78 \\
\hline \multirow{4}{*}{ type 4} & 1 & -14.20 & -17.15 & -11.81 \\
\hline & 2 & 3.69 & 3.53 & 3.85 \\
\hline & 3 & 8.21 & 8.06 & 8.33 \\
\hline & 4 & 13.93 & 13.61 & 14.28 \\
\hline \multirow{4}{*}{ type 5} & 1 & -25.49 & -30.04 & -21.99 \\
\hline & 2 & 6.24 & 6.04 & 6.44 \\
\hline & 3 & 13.45 & 13.29 & 13.62 \\
\hline & 4 & 22.96 & 22.55 & 23.42 \\
\hline \multirow{4}{*}{ type 6} & 1 & -29.56 & -34.31 & -25.80 \\
\hline & 2 & 6.24 & 6.04 & 6.44 \\
\hline & 3 & 13.98 & 13.81 & 14.17 \\
\hline & 4 & 24.55 & 24.12 & 25.01 \\
\hline \multirow{4}{*}{ type 7} & 1 & -29.58 & -34.34 & -25.82 \\
\hline & 2 & 6.24 & 6.04 & 6.44 \\
\hline & 3 & 14.00 & 13.82 & 14.18 \\
\hline & 4 & 24.58 & 24.14 & 25.04 \\
\hline \multirow{4}{*}{ type 8} & 1 & -31.68 & -36.42 & -27.78 \\
\hline & 2 & 6.59 & 6.37 & 6.80 \\
\hline & 3 & 14.83 & 14.66 & 15.02 \\
\hline & 4 & 25.87 & 25.44 & 26.35 \\
\hline \multirow{4}{*}{ type 9} & 1 & -32.62 & -37.41 & -28.70 \\
\hline & 2 & 6.85 & 6.61 & 7.08 \\
\hline & 3 & 15.41 & 15.23 & 15.60 \\
\hline & 4 & 26.77 & 26.33 & 27.26 \\
\hline \multirow{4}{*}{ type 10} & 1 & -39.75 & -44.85 & -35.10 \\
\hline & 2 & 7.12 & 6.85 & 7.37 \\
\hline & 3 & 16.80 & 16.60 & 17.02 \\
\hline & 4 & 29.16 & 28.67 & 29.67 \\
\hline \multirow{4}{*}{ type 11} & 1 & -43.49 & -48.89 & -38.93 \\
\hline & 1 & 5.89 & 5.47 & 6.34 \\
\hline & 2 & 17.03 & 16.82 & 17.26 \\
\hline & 3 & 29.82 & 29.34 & 30.32 \\
\hline \multirow{4}{*}{ type 12} & 1 & -57.44 & -63.22 & -51.98 \\
\hline & 2 & 4.46 & 3.87 & 5.09 \\
\hline & 3 & 18.01 & 17.77 & 18.25 \\
\hline & 4 & 32.22 & 31.71 & 32.78 \\
\hline
\end{tabular}


Table 5: Bootstraped standard errors for proposition 1 with relative income change: difference in equivalent income from baseline to proposed reform

\begin{tabular}{|c|c|c|c|c|}
\hline & quartile & Reform-2012 & 0.95 c.i. & 0.95 c.i. \\
\hline \multirow{4}{*}{ type 1} & 1 & 0.00 & 0.00 & 0.00 \\
\hline & 2 & 0.00 & 0.00 & 0.00 \\
\hline & 3 & 0.00 & 0.00 & 0.00 \\
\hline & 4 & 0.00 & 0.00 & 0.00 \\
\hline \multirow{4}{*}{ type 2} & 1 & -0.00 & -0.00 & -0.00 \\
\hline & 2 & 0.00 & 0.00 & 0.00 \\
\hline & 3 & 0.00 & 0.00 & 0.00 \\
\hline & 4 & 0.00 & 0.00 & 0.00 \\
\hline \multirow{4}{*}{ type 3} & 1 & -0.00 & -0.00 & -0.00 \\
\hline & 2 & 0.00 & 0.00 & 0.00 \\
\hline & 3 & 0.00 & 0.00 & 0.00 \\
\hline & 4 & 0.00 & 0.00 & 0.00 \\
\hline \multirow{4}{*}{ type 4} & 1 & -0.01 & -0.01 & -0.00 \\
\hline & 2 & 0.01 & 0.01 & 0.01 \\
\hline & 3 & 0.01 & 0.01 & 0.01 \\
\hline & 4 & 0.01 & 0.01 & 0.01 \\
\hline \multirow{4}{*}{ type 5} & 1 & -0.01 & -0.01 & -0.01 \\
\hline & 2 & 0.01 & 0.01 & 0.01 \\
\hline & 3 & 0.01 & 0.01 & 0.02 \\
\hline & 4 & 0.02 & 0.02 & 0.02 \\
\hline \multirow{4}{*}{ type 6} & 1 & -0.01 & -0.01 & -0.01 \\
\hline & 2 & 0.01 & 0.01 & 0.01 \\
\hline & 3 & 0.02 & 0.02 & 0.02 \\
\hline & 4 & 0.02 & 0.02 & 0.02 \\
\hline \multirow{4}{*}{ type 7} & 1 & -0.01 & -0.01 & -0.01 \\
\hline & 2 & 0.01 & 0.01 & 0.01 \\
\hline & 3 & 0.02 & 0.02 & 0.02 \\
\hline & 4 & 0.02 & 0.02 & 0.02 \\
\hline \multirow{4}{*}{ type 8} & 1 & -0.01 & -0.01 & -0.01 \\
\hline & 2 & 0.01 & 0.01 & 0.01 \\
\hline & 3 & 0.02 & 0.02 & 0.02 \\
\hline & 4 & 0.02 & 0.02 & 0.02 \\
\hline \multirow{4}{*}{ type 9} & 1 & -0.01 & -0.01 & -0.01 \\
\hline & 2 & 0.01 & 0.01 & 0.01 \\
\hline & 3 & 0.02 & 0.02 & 0.02 \\
\hline & 4 & 0.02 & 0.02 & 0.02 \\
\hline \multirow{4}{*}{ type 10} & 1 & -0.01 & -0.01 & -0.01 \\
\hline & 2 & 0.01 & 0.01 & 0.01 \\
\hline & 3 & 0.02 & 0.02 & 0.02 \\
\hline & 4 & 0.02 & 0.02 & 0.02 \\
\hline \multirow{4}{*}{ type 11} & 1 & -0.01 & -0.02 & -0.01 \\
\hline & 2 & 0.01 & 0.01 & 0.01 \\
\hline & 3 & 0.02 & 0.02 & 0.02 \\
\hline & 4 & 0.02 & 0.02 & 0.02 \\
\hline \multirow{4}{*}{ type 12} & 1 & -0.02 & -0.02 & -0.02 \\
\hline & 2 & 0.01 & 0.01 & 0.01 \\
\hline & 3 & 0.02 & 0.02 & 0.02 \\
\hline & 4 & 0.02 & 0.02 & 0.02 \\
\hline
\end{tabular}


Table 6: Bootstrapped standard errors for proposition 2, absolute income change

\begin{tabular}{rrrr}
\hline type & Reform-2012 & 0.95 c.i. & 0.95 c.i. \\
\hline 1 & 0.0009 & -0.0000 & 0.0016 \\
2 & 0.0601 & 0.0245 & 0.0928 \\
3 & 0.0798 & 0.0405 & 0.1157 \\
4 & 0.6118 & 0.4752 & 0.7395 \\
5 & 1.0911 & 0.8527 & 1.2987 \\
6 & 1.0793 & 0.8400 & 1.2857 \\
7 & 1.0793 & 0.8400 & 1.2857 \\
8 & 1.0781 & 0.8370 & 1.2870 \\
9 & 1.0822 & 0.8409 & 1.2899 \\
10 & 1.0232 & 0.7732 & 1.2373 \\
11 & 0.9979 & 0.7495 & 1.2130 \\
12 & 0.7775 & 0.5205 & 1.0028 \\
\hline
\end{tabular}

Table 7: Bootstrapped standard errors for proposition 2, absolute income change

\begin{tabular}{rrrr}
\hline type & Reform-2012 & 0.95 c.i. & 0.95 c.i. \\
\hline 1 & 0.000002 & 0.000001 & 0.000002 \\
2 & 0.000130 & 0.000114 & 0.000147 \\
3 & 0.000171 & 0.000153 & 0.000189 \\
4 & 0.001000 & 0.000921 & 0.001071 \\
5 & 0.001908 & 0.001805 & 0.002007 \\
6 & 0.001924 & 0.001819 & 0.002022 \\
7 & 0.001924 & 0.001819 & 0.002022 \\
8 & 0.001935 & 0.001830 & 0.002034 \\
9 & 0.001939 & 0.001835 & 0.002039 \\
10 & 0.001948 & 0.001845 & 0.002048 \\
11 & 0.001942 & 0.001840 & 0.002042 \\
12 & 0.001913 & 0.001809 & 0.002014 \\
\hline
\end{tabular}


Table 8: Bootstrapped standard errors for proposition 3, absolute income change

\begin{tabular}{|c|c|c|c|c|}
\hline & quartile & Reform-2012 & 0.95 c.i. & 0.95 c.i. \\
\hline \multirow{4}{*}{ type 1} & 1 & -0.0088 & -0.0087 & -0.0087 \\
\hline & 2 & 0.1681 & 0.1683 & 0.1683 \\
\hline & 3 & 0.2687 & 0.2689 & 0.2689 \\
\hline & 4 & 0.3131 & 0.3131 & 0.3131 \\
\hline \multirow{4}{*}{ type 2} & 1 & -3.6172 & -5.2998 & -2.2599 \\
\hline & 2 & -2.8789 & -4.5721 & -1.5050 \\
\hline & 3 & -0.8313 & -2.5549 & 0.5608 \\
\hline & 4 & 2.8315 & 1.0539 & 4.2423 \\
\hline \multirow{4}{*}{ type 3} & 1 & -3.6431 & -7.2562 & -0.8676 \\
\hline & 2 & -2.5007 & -6.0278 & 0.2609 \\
\hline & 3 & 0.5540 & -3.0187 & 3.3287 \\
\hline & 4 & 6.0520 & 2.3919 & 8.8899 \\
\hline \multirow{4}{*}{ type 4} & 1 & -8.1517 & -14.1249 & -3.6771 \\
\hline & 2 & -4.4585 & -10.3935 & 0.0298 \\
\hline & 3 & 3.7476 & -2.2436 & 8.2584 \\
\hline & 4 & 17.6804 & 11.6324 & 22.2341 \\
\hline \multirow{4}{*}{ type 5} & 1 & -7.8128 & -16.9805 & -0.7101 \\
\hline & 2 & -1.5711 & -10.7225 & 5.5808 \\
\hline & 3 & 11.8829 & 2.6335 & 18.9969 \\
\hline & 4 & 34.8454 & 25.4995 & 41.9752 \\
\hline \multirow{4}{*}{ type 6} & 1 & 5.2883 & -8.2299 & 15.5970 \\
\hline & 2 & 11.5300 & -1.9736 & 21.7831 \\
\hline & 3 & 25.5113 & 11.9063 & 35.8058 \\
\hline & 4 & 50.0657 & 36.6219 & 60.3783 \\
\hline \multirow{4}{*}{ type 7} & 1 & 20.4890 & 2.5848 & 34.4817 \\
\hline & 2 & 26.7331 & 8.8548 & 40.6459 \\
\hline & 3 & 40.7284 & 22.7248 & 54.7051 \\
\hline & 4 & 65.3094 & 47.4113 & 79.2540 \\
\hline \multirow{4}{*}{ type 8} & 1 & 33.6253 & 11.5224 & 51.2655 \\
\hline & 2 & 40.2150 & 18.1273 & 57.8608 \\
\hline & 3 & 55.0463 & 32.8530 & 72.7351 \\
\hline & 4 & 80.9128 & 58.9543 & 98.6384 \\
\hline \multirow{4}{*}{ type 9} & 1 & 48.2904 & 22.0546 & 69.6664 \\
\hline & 2 & 55.1372 & 28.9400 & 76.4689 \\
\hline & 3 & 70.5506 & 44.2744 & 91.7646 \\
\hline & 4 & 97.3181 & 71.1979 & 118.4907 \\
\hline \multirow{4}{*}{ type 10} & 1 & 57.5679 & 26.8341 & 83.5475 \\
\hline & 2 & 64.6845 & 33.9379 & 90.5895 \\
\hline & 3 & 81.4863 & 50.6235 & 107.3038 \\
\hline & 4 & 110.6472 & 79.5839 & 136.3734 \\
\hline \multirow{4}{*}{ type 11} & 1 & 67.1599 & 30.8630 & 97.4495 \\
\hline & 2 & 73.0531 & 36.7151 & 103.2175 \\
\hline & 3 & 90.0849 & 53.7811 & 120.0970 \\
\hline & 4 & 119.9013 & 83.3289 & 149.9001 \\
\hline \multirow{4}{*}{ type 12} & 1 & 62.4576 & 21.1756 & 97.1253 \\
\hline & 2 & 66.9217 & 25.5490 & 101.6260 \\
\hline & 3 & 84.9269 & 43.6518 & 119.5319 \\
\hline & 4 & 117.1482 & 75.8654 & 151.9744 \\
\hline
\end{tabular}


Table 9: Bootstrapped standard errors for proposition 3, relative income change

\begin{tabular}{|c|c|c|c|c|}
\hline & quartile & Reform-2012 & 0.95 c.i. & 0.95 c.i. \\
\hline \multirow{4}{*}{ type 1} & 1 & 0.0000 & 0.0000 & 0.0000 \\
\hline & 2 & 0.0002 & 0.0002 & 0.0002 \\
\hline & 3 & 0.0005 & 0.0005 & 0.0005 \\
\hline & 4 & 0.0006 & 0.0006 & 0.0006 \\
\hline \multirow{4}{*}{ type 2} & 1 & -0.0007 & -0.0011 & -0.0003 \\
\hline & 2 & 0.0009 & 0.0004 & 0.0013 \\
\hline & 3 & 0.0034 & 0.0029 & 0.0039 \\
\hline & 4 & 0.0058 & 0.0053 & 0.0064 \\
\hline \multirow{4}{*}{ type 3} & 1 & 0.0036 & 0.0026 & 0.0044 \\
\hline & 2 & 0.0057 & 0.0047 & 0.0067 \\
\hline & 3 & 0.0096 & 0.0085 & 0.0107 \\
\hline & 4 & 0.0134 & 0.0123 & 0.0146 \\
\hline \multirow{4}{*}{ type 4} & 1 & 0.0083 & 0.0064 & 0.0099 \\
\hline & 2 & 0.0148 & 0.0127 & 0.0166 \\
\hline & 3 & 0.0242 & 0.0221 & 0.0261 \\
\hline & 4 & 0.0338 & 0.0317 & 0.0359 \\
\hline \multirow{4}{*}{ type 5} & 1 & 0.0250 & 0.0220 & 0.0278 \\
\hline & 2 & 0.0356 & 0.0324 & 0.0385 \\
\hline & 3 & 0.0504 & 0.0472 & 0.0536 \\
\hline & 4 & 0.0663 & 0.0629 & 0.0695 \\
\hline \multirow{4}{*}{ type 6} & 1 & 0.0561 & 0.0518 & 0.0601 \\
\hline & 2 & 0.0667 & 0.0623 & 0.0709 \\
\hline & 3 & 0.0823 & 0.0778 & 0.0867 \\
\hline & 4 & 0.0994 & 0.0948 & 0.1039 \\
\hline \multirow{4}{*}{ type 7} & 1 & 0.0892 & 0.0833 & 0.0947 \\
\hline & 2 & 0.0998 & 0.0939 & 0.1054 \\
\hline & 3 & 0.1154 & 0.1093 & 0.1211 \\
\hline & 4 & 0.1325 & 0.1264 & 0.1383 \\
\hline \multirow{4}{*}{ type 8} & 1 & 0.1216 & 0.1142 & 0.1284 \\
\hline & 2 & 0.1327 & 0.1250 & 0.1398 \\
\hline & 3 & 0.1489 & 0.1413 & 0.1561 \\
\hline & 4 & 0.1669 & 0.1592 & 0.1741 \\
\hline \multirow{4}{*}{ type 9} & 1 & 0.1556 & 0.1465 & 0.1639 \\
\hline & 2 & 0.1670 & 0.1577 & 0.1755 \\
\hline & 3 & 0.1836 & 0.1744 & 0.1922 \\
\hline & 4 & 0.2021 & 0.1928 & 0.2107 \\
\hline \multirow{4}{*}{ type 10} & 1 & 0.1889 & 0.1782 & 0.1987 \\
\hline & 2 & 0.2005 & 0.1898 & 0.2105 \\
\hline & 3 & 0.2182 & 0.2073 & 0.2285 \\
\hline & 4 & 0.2380 & 0.2270 & 0.2484 \\
\hline \multirow{4}{*}{ type 11} & 1 & 0.2238 & 0.2116 & 0.2351 \\
\hline & 2 & 0.2349 & 0.2227 & 0.2466 \\
\hline & 3 & 0.2528 & 0.2403 & 0.2647 \\
\hline & 4 & 0.2730 & 0.2604 & 0.2849 \\
\hline \multirow{4}{*}{ type 12} & 1 & 0.2556 & 0.2418 & 0.2685 \\
\hline & 2 & 0.2662 & 0.2523 & 0.2793 \\
\hline & 3 & 0.2850 & 0.2709 & 0.2982 \\
\hline & 4 & 0.3066 & 0.2923 & 0.3198 \\
\hline
\end{tabular}

